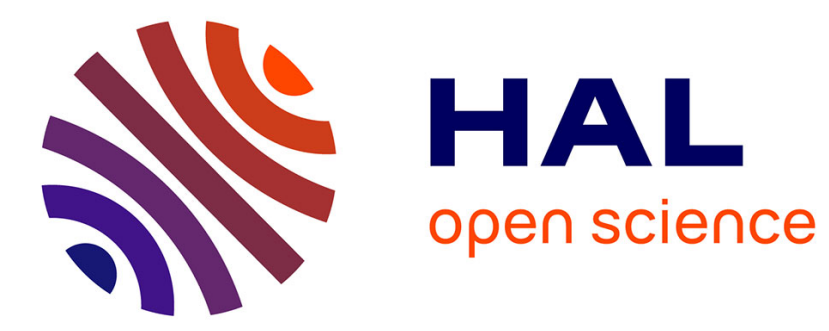

\title{
A Framework for Identification of Complexity Drivers in Manufacturing Companies
}

\author{
Rasmus Andersen, Thomas D. Brunoe, Kjeld Nielsen
}

\section{To cite this version:}

Rasmus Andersen, Thomas D. Brunoe, Kjeld Nielsen. A Framework for Identification of Complexity Drivers in Manufacturing Companies. IFIP International Conference on Advances in Production Management Systems (APMS), Sep 2019, Austin, TX, United States. pp.392-399, 10.1007/978-3030-30000-5_49. hal-02419267

\section{HAL Id: hal-02419267 https://hal.inria.fr/hal-02419267}

Submitted on 19 Dec 2019

HAL is a multi-disciplinary open access archive for the deposit and dissemination of scientific research documents, whether they are published or not. The documents may come from teaching and research institutions in France or abroad, or from public or private research centers.
L'archive ouverte pluridisciplinaire HAL, est destinée au dépôt et à la diffusion de documents scientifiques de niveau recherche, publiés ou non, émanant des établissements d'enseignement et de recherche français ou étrangers, des laboratoires publics ou privés. 


\title{
A Framework for Identification of Complexity Drivers in Manufacturing Companies
}

\author{
Rasmus Andersen(四)[0000-0001-6788-8217], Thomas D. Brunoe ${ }^{[0000-0002-9847-6562]}$ and Kjeld \\ Nielsen ${ }^{[0000-0002-3720-167 X]}$ \\ Department of Materials and Production, Aalborg University, Aalborg, Denmark \\ rasmus@mp. aau. dk
}

\begin{abstract}
The initial issue of complexity management in companies is the identification of the drivers of complexity. However, current literature lacks methods for assisting practitioners in the initial identification of such drivers. This paper, therefore, presents a novel framework for assisting practitioners with identifying complexity drivers in manufacturing companies. The framework uses a generic value chain and a generic product structure as its two dimensions. Multiple workshops are then conducted with company representatives across different value chain fields focusing on two main parts: First, surveys are used to assign complexity ratings to different generic product structure elements. Secondly, the complexity ratings are elaborated on by workshop participants. The process provides valuable insights into the perceived complexity drivers. The framework is then verified through a case study in the process industry. Based on the case study, multiple complexity drivers were identified across both value chain fields and product structure elements. The case study findings show that the framework facilitates practitioners in identifying organization-wide perceived complexity drivers. The framework contributes to both industry and research by addressing a neglected aspect of complexity management. It achieves this by providing a comprehensive and structured approach for the initial identification of complexity drivers across product elements and value chain fields.
\end{abstract}

Keywords: Complexity management, complexity driver, identification, framework, manufacturing.

\section{Introduction}

Globalized markets, increasingly heterogeneous customer requirements, and demands for lower costs are factors pressuring the competitiveness of traditional manufacturing companies [1]. These factors have resulted in increased external complexity for manufacturers. In response, companies have increased the complexity of their own operations to accommodate these changed conditions [1,2], often resulting in increased costs and reduced performance [3]. Such costs are identified across organizations in supply chain management $[3,4]$, production systems $[5,6]$, and various internal projects [7, 8]. However, complexity is not always undesirable, and may even be a source of competitive advantage [8], if managed properly. Most companies are aware of the adverse 
effects of complexity [1]. Yet, despite attention from industry concrete tools to effectively handle complexity related issues in manufacturing companies are lacking [1]. Due to the issues arising from increased complexity in companies complexity management has received increased attention in literature in the last decade [1]. However, before complexity can be managed, it must be understood what causes it [1]. These "causes" are referred to as complexity drivers in literature. Examples of complexity drivers in manufacturing companies include variety $[3,9]$ and novelty [7] of products, as well as variety of assembly equipment [6]. Identification of complexity drivers is, therefore, critical for the subsequent operationalization and quantification of the complexity costs incurred for the company [1], and investigating this perspective therefore forms the motivation of this paper.

The remainder of the paper is structured as follows: Section 2 reviews existing research on identification of complexity drivers in manufacturing industry. Based on these findings, Section 3 presents a novel framework aimed at assisting practitioners in this endeavor. Section 4 then introduces the methodology of the case study followed by Section 5, which presents the findings from the case study. Section 6 discusses the limitations of the framework after which Section 7 concludes on the major findings and suggests areas for further research.

\section{Literature Review on Complexity Driver Identification}

Literature has been reviewed for frameworks to assist in identification of complexity drivers in manufacturing companies. This review consisted of a two-step process. First, relevant papers referenced in Vogel and Lasch [1] were reviewed resulting in 9 papers. Secondly, to ensure the inclusion of the most current research a block search was performed in Elsevier's Scopus and Clarivate's Web of Science covering the period from 2016 to 2019, using the search string: "complexity driver*" OR (driver* NEAR/3 complexity) AND (identi*). Upon screening the 19 papers retrieved, the literature search produced 11 relevant papers. Since this paper focuses on the identification of complexity drivers in industry, all identified papers have been analyzed as follows: First, the identified papers are reviewed concerning the repeatability of the methods presented, as this is considered an important factor for applicability by practitioners. This is evaluated according to the degree of detail with which the initial method of gathering complexity driver data is described. Secondly, the intended usage area of the frameworks is categorized. This is to determine whether the frameworks are intended for general use in manufacturing companies, or specific to a certain subject area such as flexible assembly systems. Due to space constraints, the general findings from the papers referenced by Vogel and Lasch [1] are briefly summarized first. Hereafter, the overall findings from the database searches are presented.

Reviewing the papers cited by Vogel and Lasch [1] found that these are concerned with diverse application areas including the remanufacturing industry, supply chains, and various organizational projects. Furthermore, most of these papers rely on qualitative methods for the identification of complexity drivers, such as literature reviews, interviews, and expert reviews. However, the description of the methods used is in most 
cases not sufficiently detailed to be replicated by practitioners. For the papers where the methods are described relatively detailed, the methodologies do not allow for adaptation to specific contexts or does not provide a company-wide perspective on complexity issues.

To provide an easier overview of the findings of the subsequent database searches and literature review, the overall results have been summarized in Table 1.

Table 1. Reviewed literature categorized according to methods used in identification of complexity drivers as well as the generalizability of the frameworks.

\begin{tabular}{l|l|l}
\hline Paper & $\begin{array}{l}\text { Complexity driver data collection } \\
\text { method }\end{array}$ & $\begin{array}{l}\text { Complexity driver fo- } \\
\text { cus area }\end{array}$ \\
\hline Asadi et al. [6] & Brainstorming, questionnaire & Assembly system \\
\hline Kohr et al. [9] & Interview & Manufacturing industry \\
\hline Kohr et al. [5] & $\begin{array}{l}\text { Simulation study, interview, question- } \\
\text { naire, literature review }\end{array}$ & Manufacturing industry \\
\hline Latos et al. [8] & Interview & Organizational projects \\
\hline Leang et al. [10] & Not specified & Manufacturing industry \\
\hline Piya et al. [3] & Literature review, expert review & Supply chain \\
\hline Schmid et al. [11] & Not specified & Production equipment \\
\hline Schuh et al. [12] & Literature review, expert review & Organizational projects \\
\hline Schuh et al. [13] & Literature review & Organizational projects \\
\hline Schuh et al. [7] & Not specified & Organizational projects \\
\hline Sun et al. [4] & Questionnaire, expert review, workshop & Supply chain \\
\hline
\end{tabular}

Asadi et al. [6] acknowledges the need for adapting the complexity driver identification method to specific contexts by allowing survey respondents to add missing complexity drivers. Regardless of the fundamental method used for identifying complexity drivers, Kohr et al. [5] notes that the analysts must determine the relevant sources to use, further implying a focus on context specificity. Most of the literature reviewed base their approach on qualitative methods. Specifically, only 1 out of 11 publications reviewed base their methodology on quantitative methods. Kohr et al. [5] notes that given existing data models, a quantitative approach for identifying complexity drivers may be less resource demanding than a qualitative approach. They contribute this to the manual work involved in designing, performing, and analyzing surveys and interviews [5]. However, for companies where the necessary quantitative data is unavailable, using a qualitative approach may be favorable from a resource perspective. Furthermore, although often considered as inherently objective, data models are still subject to the perspective chosen by the data analyst, thereby questioning the objectivity of the quantitative approach [5].

The results of the literature review indicate that there is a gap in literature concerning detailed and concrete methods for the initial identification of complexity drivers. This presents an issue for both researchers and practitioners undertaking complexity reduction efforts and is therefore important to address. 


\section{Framework for Identification of Complexity Drivers}

Based on the identified gap in the existing literature, this section presents a novel framework for the initial identification of perceived complexity drivers in a manufacturing company. The framework constitutes two parts: i) the structure of the framework and ii) the associated process to follow. These parts will be described in the following.

\subsection{Framework Structure}

The framework is structured as a multi-dimensional matrix and is illustrated in Fig. 1.

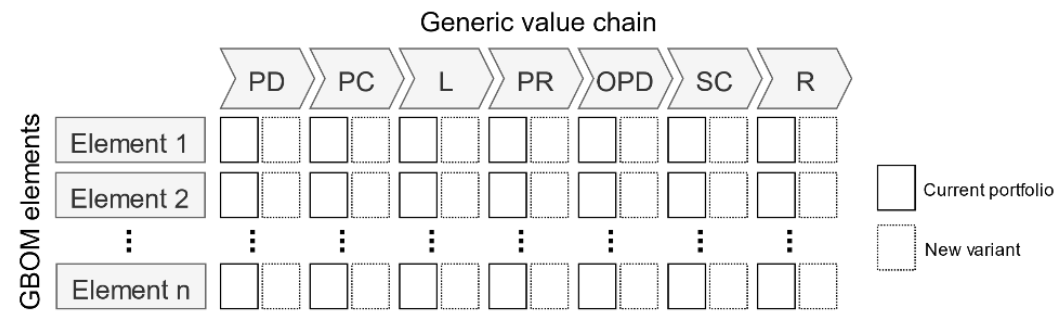

Fig. 1. The generic complexity driver identification framework.

The first outer dimension of the framework is a representation of a generic value chain using the seven fields summarized by Vogel and Lasch [1]. The value chain fields are product development (PD), procurement (PC), logistics (L), production (PR), order processing/distribution/sale (OPD), internal supply chain (SC), and remanufacturing (R). Taking outset in a generic value chain makes the framework generally applicable within the manufacturing industry. The framework can be adapted to individual companies by subtracting irrelevant value chain fields, such as the remanufacturing field for companies not engaged in this activity. The second outer dimension of the framework is the generic product structure, which has been implemented through the generic bill-of-materials (GBOM) introduced by Hegge and Wortmann [14]. Describing product families through a generic product structure enables coverage of the full breadth of product variants with only one representation [14]. Providing the intersection between the two dimensions of the framework is the complexity rating matrix. For each GBOM element and value chain field, two values must be provided. The first value denotes the perceived complexity of managing the existing portfolio of GBOM element variants. The second value denotes the perceived complexity associated with adding a new variant to the portfolio. By including complexity ratings for both existing and new GBOM element variants, a holistic perspective of complexity related issues is maintained.

\subsection{Framework Process}

The second part of the framework is the process which enables application of the framework in practice. To ensure inclusion of all value chain fields, workshops should be 
scheduled for each and include company representatives from corresponding departments. The process involves three overall phases. First, at the beginning of each workshop, a brief introduction to the purpose and objective of the workshop is given. Secondly, the workshop participants are then asked to collectively rate their perceived complexity of each GBOM element. This is done by using a five-point Likert scale, where 1 represents the lowest perceived complexity and 5 the highest perceived complexity. Lastly, based on the complexity ratings provided, the participants are asked to elaborate on each individual rating. This process provides the analysts with valuable insights into which aspects of each GBOM element that are considered complexity drivers by the workshop participants. Through this process, analysts can gather information about potential complexity drivers in their organizations as well as the perceived importance of these. This forms a foundation for further analysis of the costs incurred by each of these perceived drivers of complexity, which in turn guides managers to where complexity reduction initiatives are most needed in their organizations.

\section{Methodology}

To verify the framework and illustrate its applicability in industry it has been applied in a case company. This section first introduces the case company and then describes the approach followed for the workshops conducted.

\subsection{Case Description}

The case company is a mid-sized production company operating in the business-tobusiness market. The company's main product range is liquid household chemicals produced on either fully or semi-automated production lines. The company is experiencing challenges caused by market developments like those referenced in Section 1. This has resulted in a product portfolio which has grown steadily and includes several hundred product variants and a high rate of annual renewal of the portfolio. For these reasons, the company has recently initiated a complexity management program. The company, therefore, makes for an interesting case for studying methods for identification of complexity drivers. During this study, information was primarily obtained through active participation in workshops and interviews with company representatives. Additionally, company records were used in constructing the GBOM.

\subsection{Case Study Procedure}

In preparation for the workshops, the $\mathrm{BOMs}$ for the liquid chemical product group were analyzed to extract the GBOM. The GBOM was then verified by product developers from the company. The resulting product structure comprises the five generic elements: cap, bottle, formula, label, and packaging. The generic value chain fields were verified by managers resulting in exclusion of remanufacturing. Workshops were then scheduled with between two and four representatives from departments corresponding to the 
value chain fields in the framework. The participants included both managers and specialists, thereby providing insights from both an overall and detailed perspective. Initiating each workshop was a brief introduction to the overall complexity management program followed by an introduction to the framework and purpose of the workshop. Following the introduction, a printout of the framework was handed to the participants, whom were then asked to collectively rate their perceived complexity of each of the five generic subassemblies. To ensure that the participants were not influenced by the ratings made by other departments, a blank framework template was used for each workshop. Once all ratings had been submitted, the participants were asked to elaborate on their ratings by describing them using short keyword sentences on post-its. The postits were then grouped based on which of the five generic subassemblies they referenced.

\section{$5 \quad$ Case Study Findings}

Combining the scores from each individual workshop conducted in the case company resulted in the complexity ratings shown in Fig. 2. The ratings have been color-coded based on their severity. Based on the total ratings for each GBOM element, it is found that "Bottle" and "Formula" are the overall highest rated, each with a total score of 39. They can therefore be considered nearly identical in perceived complexity. The complexity ratings for these two subsystems are also close in a majority of the value chain fields. For example, their ratings differ by no more than one score in 9 out of the 12 value chain ratings. Examples of complexity drivers mentioned for the "Bottle" subsystem includes long changeovers when changing between bottle formats in production and high inventory space taken up by bottles when compared with their consumption rate in production. The complexity drivers mentioned for the "Formula" subsystem includes having to revise production schedules when new variants are added to the production mix, as well as getting changes to formulas approved by certification organizations and customers. On the other hand, labels are generally rated as resulting in least complexity for the company, with a total score of just 21 . Complexity drivers mentioned for this subsystem are having to track a high number of variants in both physical inventory and keeping them up to date in the ERP system. In total, more than 53 different complexity drivers were mentioned for the five GBOM elements. Considering the value chain fields, it appears that complexity challenges are mostly affecting the logistics and production fields. In comparison, the procurement and supply chain fields appear less affected by complexity, especially when considering complexity related to new variants. In general, visualization of the perceived complexity through the complexity ratings in addition to the complexity drivers enables managers to make decisions concerning where to focus future analysis of complexity costs and subsequent complexity reduction efforts. 


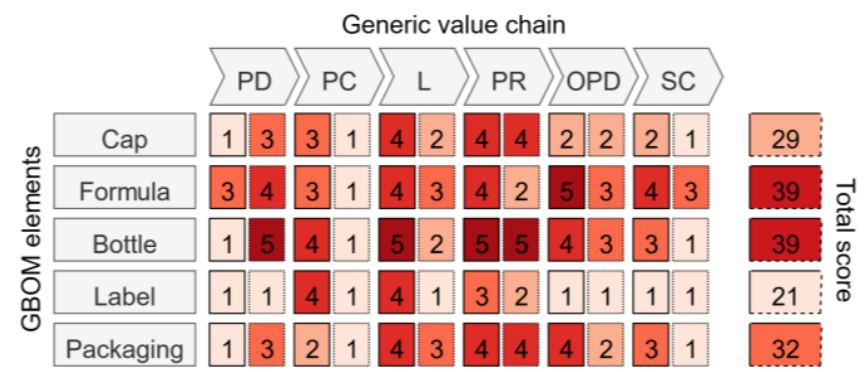

Fig. 2. Complexity rating results from applying the framework in the case company.

\section{Discussion}

The aim of the presented framework is to assist practitioners in the initial phase of complexity driver identification: exploring perceived complexity drivers. The case study showed that the framework succeeds in this regard. However, potential limitations of the framework have been noted. The GBOM representation is limited to products similar in structure. Complexity exploration may thus be limited in scope in companies, where the entire product portfolio cannot be represented by a single generic GBOM. Furthermore, while the products analyzed in the case study are simple, consisting of only a handful of elements, very complex products such as automobiles may pose a challenge to manage in the framework. For such products, a different unit of analysis may ensure a manageable level of detail. This may involve either using highlevel subsystems (e.g. drivetrain, body, chassis, etc.) or focusing on only a single highlevel subsystem (e.g. only drivetrain) and its constituent subsystems. While the framework relies on qualitative data to assess perceived complexity, using quantitative data and automated data processing may facilitate a dynamic framework implemented in e.g., a business intelligence solution. However, pursuing this direction would entail a different set of challenges concerning how complexity-related costs are measured accurately. Another aspect, which may question the validity of the framework is using combined scores for existing and new product variants. If the two aspects have different units of magnitude, weighing them equally risk skewing the results of the framework.

\section{Conclusion}

In this paper we have presented a framework to assist practitioners in the identification of context specific complexity drivers. The framework achieves this by means of the generic value chain and generic bill-of-materials, with the former ensuring a broad perspective on complexity drivers and the latter a detailed insight into these. The framework has been verified in a case company where it facilitated the identification of complexity drivers across company functions and product elements. The combination of the complexity ratings and the identified complexity drivers further assists practitioners in focusing their subsequent investigations of where complexity reduction initiatives in their organization should be directed. 
Further research should be aimed at investigating both limitations and potentials of the framework. This involves investigating the applicability of the framework for more complex products as well as the applicability in organizations with dissimilar product structures. Given the framework's focus on application by practitioners, further research should center on prescriptive analytics and address how the results of the framework should be interpreted in addition to presenting guidelines on what actions to take.

\section{References}

1. Vogel, W., Lasch, R.: Complexity drivers in manufacturing companies: a literature review. Logist. Res. 9, 25 (2016). doi:10.1007/s12159-016-0152-9

2. Seifert, S., Butzer, S., Westermann, H.-H., Steinhilper, R.: Managing Complexity in Remanufacturing. In: Proceedings of the World Congress on Engineering 2013. pp. 730738. , London (2013)

3. Piya, S., Shamsuzzoha, A., Miftaur Rahman Khan Khadem, M., Al Kindi, M.: Supply Chain Complexity Drivers and Solution Methods. Int. J. Supply Chain Manag. 6, 43-50 (2017)

4. Sun, C., Rose, T., Ehm, H., Herbig, T.: Best Practice Sharing for Complexity Management in Supply Chains of the Semiconductor Industry. In: Procedia CIRP. pp. 538-543 (2016)

5. Kohr, D., Friedli, T., Vera, D., Ahmad, M., Kaniappan Chinnathai, M., Harrison, R., Budde, L., Alkan, B.: Proposing a Holistic Framework for the Assessment and Management of Manufacturing Complexity through Data-centric and Human-centric Approaches. In: COMPLEXIS. pp. 86-93 (2018)

6. Asadi, N., Jackson, M., Fundin, A.: Drivers of Complexity in a Flexible Assembly SystemA Case Study. Procedia CIRP. 41, 189-194 (2016). doi:10.1016/j.procir.2015.12.082

7. Schuh, G., Rudolf, S., Mattern, C.: Conceptual framework for evaluation of complexity in new product development projects. In: 2016 IEEE International Conference on Industrial Technology (ICIT). pp. 1022-1027. IEEE (2016)

8. Latos, B.A., Harlacher, M., Przybysz, P.M., Mutze-Niewohner, S.: Transformation of working environments through digitalization: Exploration and systematization of complexity drivers. In: 2017 IEEE International Conference on Industrial Engineering and Engineering Management (IEEM). pp. 1084-1088. IEEE (2017)

9. Kohr, D., Budde, L., Friedli, T.: Identifying Complexity Drivers in Discrete Manufacturing and Process Industry. Procedia CIRP. 63, 52-57 (2017). doi:10.1016/j.procir.2017.03.290

10. Leang, S.H., Wan Mahmood, W.H., Rahman, M.A.A.: The impact of manufacturing complexity drivers on performance-a preliminary study. IOP Conf. Ser. Mater. Sci. Eng. 328, 012010 (2018). doi:10.1088/1757-899X/328/1/012010

11. Schmid, A., Jacobs, G., Löwer, M., Katzwinkel, T., Schmidt, W., Siebrecht, J.: A Functional Platform Strategy for Integrated Machine Tools. In: Procedia CIRP. pp. 296-301 (2017)

12. Schuh, G., Prote, J.-P., Luckert, M., Basse, F., Thomson, V., Mazurek, W.: Adaptive Design of Engineering Change Management in Highly Iterative Product Development. Procedia CIRP. 70, 72-77 (2018). doi:10.1016/j.procir.2018.02.016

13. Schuh, G., Riesener, M., Mattern, C.: Approach to evaluate complexity in new product development projects. Int. J. Des. Nat. Ecodynamics. 11, 573-583 (2016). doi:10.2495/DNE-V11-N4-573-583

14. Hegge, H.M.H., Wortmann, J.C.: Generic bill-of-material: a new product model. Int. J. Prod. Econ. 23, 117-128 (1991). doi:10.1016/0925-5273(91)90055-X 